\title{
RESULTS OF MEDICAL-SOCIAL RESEARCH ON MEDICAL CARE QUALITY FOR PATIENTS WITH COVID-19 OF INPATIENT HOSPITAL DEPARTMENTS IN SUMY REGION
}

DOI: 10.36740/WLek202105101

\author{
Natalia 0. Dryha', Alla V. Stepanenko², Lesia A. Rudenko³, Daria 0. Zhaldak', Svitlana M. Piven², Inna 0. Plakhtiienko' \\ 'SUMY STATE UNIVERSITY, SUMY, UKRAINE \\ ¿UKRAINIAN MILITARY MEDICAL ACADEMY, KYIV, UKRAINE \\ ${ }^{3}$ ALUNA PUBLISHING HOUSE, KONSTANCIN-JEZIORNA, POLAND
}

\begin{abstract}
The aim: The aim of the study is to assess the quality of medical care and determine the relationship between treatment outcomes of patients and acute respiratory viral infectious disease caused by SARS-CoV-2, depending on patients` age, the time from onset of symptoms to hospitalization, and the presence of comorbidity.

Materials and methods: According to the specially designed form, a retrospective analysis of primary accounting documents was carried out (f. No. 103/0) in 158 patients with COVID-19. The research was carried out in specialized inpatient infectious diseases wards of health institutions of the Sumy region during the period from April to September 2020. The study used a systemic approach, bibliosemantic, comparative and statistical analyses, logical generalization methods.

Results: Among the study group of patients, namely 158 people, a bigger number of women ( $56.33 \pm 3.95 \%)$ than men (43.67 $\pm 3.95 \%)$ were recorded. Patients of working age (from 18 to 64 years old) took $70.89 \pm 3.61 \%$ of all patients, and people aged 65 years and older $-29.11 \pm 3.61 \%$. The time from the beginning of symptoms to hospitalization in each second patient (49.37 $\pm 3.98 \%$ ) lasted 5-7 days. In most cases, the patient's stay in the hospital equaled $13-15$ bed-days $-32.28 \pm 3.72 \%$. The index of patients with severe and critical state was $20.89 \pm 3.23 \%$ (33 patients). In $8.23 \pm 2.19 \%$ (13 people) of treated cases of hospital stay ended in death. A large index of patients with a severe course of the disease, the treatment of which ended in discharge, were in hospital for more than 13 bed days $-12.03 \pm 2.59 \%$ ( 19 people). All of these patients were older, had CNCDs (chronic non-communicable diseases), half of them were hospitalized on day 7 and later from the onset of symptoms.

Conclusions: In older people, the disease progresses faster and complications are developing more often. Also, the severity of the SARS-CoV-2 pattern and the length of staying in the hospital are affected by the time starting the onset of symptoms till hospitalization and the presence of CNCDs. The hereinafter data allows to increase knowledge about spreading of COVID-19, to improve the quality of organizational and preventive events in the provision of medical care, and reducing mortality.
\end{abstract}

KEY WORDS: COVID-19, SARS-COV, pandemic, WHO, health care providing organization

Wiad Lek. 2021;74(5):1057-1060

\section{INTRODUCTION}

The situation that has developed over the past year due to the development of the pandemic of acute syndrome (SARS)-CoV-2 has become threatening. The World Health Organization (WHO) recognized the spread of COVID-19 as a pandemic on 11 March 2020 [1]. In February 2020, the Global Forum on Research and Innovation for COVID-19 convened by the WHO identified immediate research actions, medium- and long-term research priorities, and highlighted multisectoral knowledge gaps that need to be addressed to manage public health in pandemic settings. All these factors create incredible pressure on health systems at the global and local levels $[2,3]$.

According to Nanshan Chen et al., among cases, bigger number of older age men than women is registered. Previously, it was also found that MERS-CoV and SARS-CoV infect more men than women. Risk factors for severe disease have not yet been fully investigated, however, in older patients and patients with chronic diseases, the risk of a severe pattern is increasing several times. Approximately half of patients infected with SARS-CoV had chronic comorbidities, mainly cardiovascular diseases and diabetes mellitus [4].

Among confirmed cases of disease of COVID-19 in China as on February 11, 2020, mortality in patients without comorbidity was $0.9 \%$, while in persons with comorbid cardiovascular diseases $-10.5 \%$, with diabetes $7 \%$, chronic lung diseases and cancer $-6 \%$. Early detection and timely treatment of infected persons is therefore crucial. It is known that in older people the disease progresses faster and complications (e.g. multiple organ insufficiency) are developing more often $[5,6]$.

According to Tao Chen et al., the most frequent clinical presentations of coronavirus infection before the end of the first week of the disease are pneumonia, respiratory failure. The time from the onset of symptoms till the development of shortness of breath was from 5 to 13 days, severe pneumonia developed in $15.7 \%$ of patients. The average time from onset of symptoms to hospitalization was 9 (interquartile range 6-12) days for the recovered patients. For the deceased, as a rule, this time was longer - 10 (interquartile range 7-13) 
days. The average time from first symptoms to discharge among recovered patients was 26 (21-29) days. The average time from onset of symptoms to death was 16 (12-20) days. The average time from hospitalization to discharge from the hospital was 16 (14-19) days, while from hospitalization to death - 5 (3-9) days [7].

\section{THE AIM}

The aim of the study is to assess the quality of medical care and to determine the relationship between the treatment outcomes of patients with acute respiratory viral infectious disease (SARS) caused by SARS-CoV-2 and their age, the time from onset of symptoms to hospitalization, and the presence of comorbidity.

\section{MATERIALS AND METHODS}

According to the specially designed form, a retrospective analysis of the primary accounting documents was carried out (f. No. 103/o) in 158 patients with COVID-19. The research was carried out in specialized inpatient infectious diseases wards of health institutions of the Sumy region during the period from April to September 2020. The study used a systemic approach, bibliosemantic, comparative and statistical analyses, logical generalization methods. Using the functions of Google Ones and the Microsoft Excel 2010 application for Windows, the obtained data were processed and statistically analyzed: descriptive statistics, calculation of the error of the relative value $(\mathrm{m})$.

The studies were carried out in compliance with the main provisions of the "Rules of ethical principles for performing the scientific medical researches with human participation", approved by the declaration of Helsinki, ICH GCP, EEC Directive No. 609, orders of the Ministry of Health of Ukraine No. 690 dated 23.09.2009, No. 944 dated 14.12.2009 y., No. 616 dated 03.08.2012. The study protocol was approved by the biomedical ethics committee of Sumy State University, Sumy.

\section{RESULTS AND DISCUSSION}

During the study, we analyzed a total of 158 «Medical Records of Inpatients» (f. No. 103/o). Among the study group $56.33 \pm 3.95 \%$ of patients were women ( 89 people) and $43.67 \pm 3.95 \%$ were men ( 69 people). It should be noted that the greater proportion among patients was persons of working age: age $45-64$ years $-51.90 \pm 3.97 \%, 18-44$ years $-18.99 \pm 3.12 \%$. The proportion of patients aged 65 years and older equaled $29.11 \pm 3.61 \%$ (Table I).

The bigger ration of patients in the study group are coming form Sumy, namely $86.71 \pm 2.70 \%$ (137 people), residents of rural settlements of the Sumy region work out $12.66 \pm 2.65 \%$ ( 20 people), one patient arrived from another region of Ukraine.

Processing and analysis of the obtained data showed that in-patient departments for the study period, in most cases, patients with SARS (ARVI) disease caused by SARS-CoV-2 were referred by a general practitioner-family physician (GP) $-51.27 \pm 3.98 \%$ of all hospitalized, $39.87 \pm 3.90 \%-$ were sent to the hospital after an emergency physician referral. After referral by doctor - specialist physician, $6,96 \pm 2,02 \%$ of patient were hospitalized. The percent ratio of patients, who referred to the hospital themselves was only $1,90 \pm 1,09 \%$.

On day 1-3 after seeking medical advice, $85.44 \pm 2.81 \%$ of patients were hospitalized, but $14.56 \pm 2.81 \%$ of patients were hospitalized after a week or more after seeking medical advice, among whom $3.16 \pm 1.39 \%$ were hospitalized more than 10 days from first seeking medical advice.

When analyzing patients' anamneses regarding the onset of the disease and the day of hospital admission, it should be noted that only $13.29 \pm 2.70 \%$ of patients were hospitalized in the first three days since the onset of the disease. Almost half of the study group $(49.37 \pm 3.98 \%$ of patients) were hospitalized a week later from the onset of disease symptoms, another $29.75 \pm 3.64 \%$ of patients $-8-13$ days from the onset of the disease, and $5.70 \pm 1.84 \%$ of patients were hospitalized after 14 days from the onset of the disease. At $1.90 \pm 1.09 \%$ of the cases abovementioned data were missing.

When examining the duration of patients' stay in the hospital, it was established that a greater ratio of treated patients spent 13-15 bed-days in the hospital that equaled $32.28 \pm 3.72 \%$; $10-12$ bed-days were spent by $25.95 \pm 3.49 \%$ of patients; $16-18$ bed-days - by $13.92 \pm 2.75 \%$ of patients; 19 days or more - by $5.70 \pm 1.84 \%$ of patients. Among the study group, only $22.15 \pm 3.30 \%$ of patients were in hospital for less than 10 days, in whom $5.70 \pm 1.84 \%$ spent from 1 to 3 bed days ( $3.80 \pm 1.52 \%$ of fatal cases), 7-9 bed days $15.19 \pm 2.86 \%$ of patients (fatal cases $-3.16 \pm 1,39 \%$ ). All patients were discharged from the hospital on condition of an improvement of the state and after-treatment at home $-87.97 \pm 2.59 \%$ treated; in $8.23 \pm 2.19 \%$ (13 people) treated cases during hospital stay ended in death, $3.80 \pm 1.52 \%$ of patients (6 people) were transferred to another medical institution due to exacerbation of comorbidity (Table II.).

It was found that the presence of comorbid chronic noncommunicable diseases (CCNCD) such as diseases of the cardiovascular system (CVD), respiratory organs (ROD), diabetes mellitus (DM) and others affect the increased risk of SARS (ARVI) caused by SARS-CoV-2 and affect the severity of its pattern. Among the study group of patients, $56.96 \pm 3.94 \%$ have CVDs, $20.25 \pm 3.20 \%$ - endocrine diseases, namely DM, 9.49 $\pm 2.33 \%$ - RODs.

The study showed that the proportion of patients with severe and critical course of SARS-CoV-2 in the sample equals $20.89 \pm 13.23 \%$ (33 people). All of these patients had CCNCD, and half of them had a time passed from onset of symptoms to hospitalization of 7 days or more. It is among this group of patients that the greatest mortality is traced $-6.33 \pm 1.94 \%$ ( 10 cases). That means that among all treated cases in people whose staying in the hospital ended in death, the proportion of hospitalized in serious or critical condition was $77 \%$.

We also analyzed the durationof staying of patients in 
Table I. Proportion of patients with ARVI caused by SARS-CoV-2, depending on sex or age (absolute numbers and \%)

\begin{tabular}{|c|c|c|c|c|}
\hline Age group & Sex & $\begin{array}{c}\text { Number of patients with COVID-19, } \\
\text { that took part in research }\end{array}$ & $\begin{array}{l}\text { Part of certain age group from } \\
\text { general audit group, in } \%\end{array}$ & $\begin{array}{l}\text { Mean ratio } \\
\text { error }(\mathbf{m}), \%\end{array}$ \\
\hline \multirow{3}{*}{$18-44$ years } & Male & 16 & 10,13 & $\pm 2,40$ \\
\hline & Female & 14 & 8,86 & $\pm 2,26$ \\
\hline & Both & 30 & 18,99 & $\pm 3,12$ \\
\hline \multirow{3}{*}{ 45-64 years } & Male & 37 & 23,42 & $\pm 3,37$ \\
\hline & Female & 45 & 28,48 & $\pm 3,59$ \\
\hline & Both & 82 & 51,90 & $\pm 3,97$ \\
\hline \multirow{3}{*}{$\begin{array}{l}65 \text { years and } \\
\text { older }\end{array}$} & Male & 16 & 10,13 & $\pm 2,40$ \\
\hline & Female & 30 & 18,99 & $\pm 3,12$ \\
\hline & Both & 46 & 29,11 & $\pm 3,61$ \\
\hline \multicolumn{2}{|c|}{ Male, total } & 69 & 43,67 & $\pm 3,95$ \\
\hline \multicolumn{2}{|c|}{ Female, total } & 89 & 56,33 & $\pm 3,95$ \\
\hline \multicolumn{2}{|c|}{ All patients } & 158 & & \\
\hline
\end{tabular}

Table II. Ratio of patients with ARVI/SARS caused by SARS-CoV-2, depending on number of bed-days, spent in hospital (absolute numbers, and \%)

\begin{tabular}{cccccccccc}
\hline Number of bed-days spent & $\mathbf{1 - 3}$ & $\mathbf{4 - 6}$ & $\mathbf{7 - 9}$ & $\mathbf{1 0 - 1 2}$ & $\mathbf{1 3 - 1 5}$ & $\mathbf{1 6 - 1 8}$ & $\mathbf{1 9}-\mathbf{2 1}$ & $\mathbf{>} \mathbf{2 1}$ \\
\hline Numbe of patients, absolute number & 9 & 2 & 24 & 41 & 51 & 22 & 7 & 2 \\
\hline Part of certain age group from general audit group, in $\%$ & 5,70 & 1,27 & 15,19 & 25,95 & 32,28 & 13,92 & 4,43 & 1,27 \\
\hline Mean ratio error $(\mathrm{m}), \%$ & $\pm 1,84$ & $\pm 0,89$ & $\pm 2,86$ & $\pm 3,49$ & $\pm 3,72$ & $\pm 2,75$ & $\pm 1,64$ & $\pm 0,89$ \\
\hline
\end{tabular}

Table III. Ratio of patients, depending on inpatient hospital staying duration and severity of the ARVI (SARS) disease course, caused by SARS-CoV-2 (bed-days, \%)

\begin{tabular}{|c|c|c|c|c|c|c|c|c|}
\hline \multirow{2}{*}{$\begin{array}{c}\text { Patients` ratio by severity of } \\
\text { disease course, } \%\end{array}$} & \multicolumn{8}{|c|}{ Patients ratio by inpatient staying duration, $\%$} \\
\hline & $1-3 \mathrm{~b} / \mathrm{d}$ & 4-6 b/d & $7-9 \mathrm{~b} / \mathrm{d}$ & $10-12 \mathrm{~b} / \mathrm{d}$ & $13-15 \mathrm{~b} / \mathrm{d}$ & $16-18 \mathrm{~b} / \mathrm{d}$ & $19-21 \mathrm{~b} / \mathrm{d}$ & $>21 \mathrm{~b} / \mathrm{d}$ \\
\hline $\begin{array}{c}\text { Middle severity course, } \\
(79,11 \pm 3,23 \%)\end{array}$ & $\begin{array}{r}1,90 \\
\pm 1,09 \\
\end{array}$ & $\begin{array}{c}1,27 \\
\pm 0,89\end{array}$ & $\begin{array}{r}12,03 \\
\pm 2,59 \\
\end{array}$ & $\begin{array}{r}24,05 \\
\pm 3,40 \\
\end{array}$ & $\begin{array}{l}27,22 \\
\pm 3,54 \\
\end{array}$ & $\begin{array}{r}8,86 \\
\pm 2,26 \\
\end{array}$ & $\begin{array}{r}2,53 \\
\pm 1,25 \\
\end{array}$ & $\begin{array}{c}1,27 \\
\pm 0,89\end{array}$ \\
\hline $\begin{array}{c}\text { Acute critical course, } \\
(20,89 \pm 3,23 \%)\end{array}$ & $\begin{array}{c}3,80 \\
\pm 1,52\end{array}$ & - & $\begin{array}{c}3,16 \\
\pm 1,39\end{array}$ & $\begin{array}{r}1,90 \\
\pm 1,09\end{array}$ & $\begin{array}{c}5,06 \\
\pm 1,74\end{array}$ & $\begin{array}{r}5,06 \\
\pm 1,74\end{array}$ & $\begin{array}{r}1,90 \\
\pm 1,09\end{array}$ & - \\
\hline
\end{tabular}

the inpatient department, depending on the severity of the disease course. The results show that most patients with a severe and critical course of SARS-CoV-2, whose treatment ended in discharge, were in hospital for more than 13 beddays $-12.03 \pm 2.59 \%$ (19 people). In $6.96 \pm 2.02 \%$ of cases, the length of staying of patients with severe and critical course of disease in hospital ranged from 1 to 7 bed days, which is explained by the high degree of lethality in this group.

Among patients with moderate disease severity in $50.63 \pm 3.98 \%$ of cases, the duration of stay in the infection department varied from 10 to 15 bed-days, in $12.66 \pm 2.65 \%$ of cases, the duration of staying was 16 days or more, less than 10 bed-days spent in hospital hsve only $15.19 \pm 2.86 \%$ patients in this group (Table III).

Our study confirmed the main differences in disease course and treatment duration in patients who died of COVID-19 and those who were cured of it. The severity of the disease course, the development of its complications, the risk of death and the duration of staying in the hospital are influenced by: patient's age, presence of concomitant CCNCD, time from the onset of symptoms to hospitalization.
The results of our study will enrich knowledge about SARS (ARVI) diseases caused by SARS-CoV-2 and their impact on the health of the population, therefore, help to reduce the mortality rate, optimize the quality of organizational and preventive events in the provision of medical care.

\section{CONCLUSIONS}

Among the study group of patients, a bigger number of women were recorded $(56.33 \pm 3.95 \%)$ than men (43.67 $\pm 3.95 \%)$. Patients of working age (from 18 to 64 years old) amounted to $70.89 \pm 3.61 \%$, patients aged 65 years and older $-29.11 \pm 3.61 \%$.

In older people, the disease progresses faster and complications develop more often. Also, the severity of the SARS-CoV-2 course and the duration of staying in the hospital are affected by the time from the onset of symptoms to hospitalization and the presence of concomitant CCNCD.

The ratio of patients with severe and critical course of SARS-CoV-2 was $20.89 \pm 3.23 \%$ (33 people). All of these 
patients had concomitant CCNCD, and half of them had a time from onset of symptoms to hospitalization of 7 days or more. It is among this group of patients that the greatest mortality is traced $-6.33 \pm 1.94 \%$ (10 cases). And patients whose treatment ended in discharge stayed in hospital for more than 13 bed-days $-12.03 \pm 2.59 \%$ (19 people).

The obtained results of medical and social research make it possible to increase knowledge about the spread of COVID-19, improve the quality of organizational and preventive events in the provision of medical care, and reduce mortality.

\section{REFERENCES}

1. World Health Organisation WHO Director-General's opening remarks at the media briefing on COVID-19. 2020. https://www.who.int/dg/ speeches/detail/who-director-general-s-opening-remarks-at-themedia-briefing-on-covid-19-11-march-2020.

2. Mullen L., Potter C., Gostin L. et al. An analysis of International Health Regulations emergency committees and public health emergency of international concern designations. BMJ Global Health. 2020;5(6):e002502. doi:10.1136/bmjgh-2020-002502.

3. Meyer D., Bishai D., Ravi S.J. et al. A checklist to improve health system resilience to infectious disease outbreaks and natural hazards. BMJ Global Health. 2020;5(8):e002429. doi:10.1136/bmjgh-2020-002429.

4. Nanshan Chen, Min Zhou, Xuan Dong et al. Epidemiological and clinical characteristics of 99 cases of 2019 novel coronavirus pneumonia in Wuhan, China: a descriptive study. Lancet. 2020;395: 507-13.

5. Singhal T.A. Review of Coronavirus Disease-2019 (COVID-19). Indian J Pediatr. 2020;87:281-286. doi.org/10.1016/50140-6736(20)30211-7.

6. Lai C.C., Shih T.P., Ko W.C. et al. Severe acute respiratory syndrome coronavirus 2 (SARS-CoV-2) and corona virus disease-2019 (COVID-19): the epidemic and the challenges. International journal of Antimicrobial Agents. 2020;55(3):105924. doi: 10.1016/j.ijantimicag.2020.105924.
7. Tao Chen, Di Wu, Huilong Chen et al. Clinical characteristics of 113 deceased patients with coronavirus disease 2019: retrospective study. BMJ. 2020;368:m1091. doi: https://doi.org/10.1136/bmj.m1091.

\section{ORCID and contributionship:}

Natalia O. Dryha: 0000-0002-1399-6834 A, B,D

Alla V. Stepanenko: 000-0002-3855-3829 A, B,E

Lesia A. Rudenko: 0000-0003-0556-8263 ${ }^{E, F}$

Daria O. Zhaldak: 0000-0002-6608-7706 ${ }^{B, C}$

Svitlana M. Piven: 0000-0002-9085-8750 A, C

Inna O. Plakhtiienko: 0000-0002-4200-8997 C, D

\section{Conflict of interest:}

The Authors declare no conflict of interest.

\section{CORRESPONDING AUTHOR Natalia 0. Dryha \\ Sumy State University \\ 2 Rimsky-Korsakov St., 40000 Sumy, Ukraine \\ tel: +380668026105 \\ e-mail:n.dryha@med.sumdu.edu.ua}

Received: 17.12 .2020

Accepted: 29.03 .2021

A - Work concept and design, B - Data collection and analysis, C - Responsibility for statistical analysis, $\mathbf{D}$-Writing the article, $\mathbf{E}$-Critical review, $\mathbf{F}$ - Final approval of the article 